\title{
ANALISIS PENYEBAB NYERI DAN KETIDAKNYAMANAN DALAM BEKERJA PADA PENGRAJIN KESET KAIN LIMBAH- PRINGAPUS SEMARANG
}

\author{
Rida Zuraida \\ Department of Industrial Engineering, Faculty of Engineering, Universitas Bina Nusantara \\ Jln. K. H. Syahdan No. 9 Palmerah Jakarta Barat 11480 \\ rzuraida@binus.edu, rzuraida@yahoo.com
}

\begin{abstract}
This research identified any kind of work condition and craftsman's posture that trigger the pain and discomfort for craftsman of doormat in Pringapus, Semarang. Observation of the work condition is conducted including work facilities and their posture during sewing process. To identify their pain and discomfort, Nordic Musculoskeletal Questionnaire (NMQ) is used as reference. The result is used as an input for rapid upper limb assessment worksheet (RULA) to determine the level of the risk. RULA's final score is indicated the conditions need further investigation and change may be needed. Based on the analysis using fishbone diagram, to overcome pain/discomfort in the area of the neck and the shoulder, high adjustment of table and seat is suggested, because the evidence shows they trigger the craftsmen's bad posture. For pain/discomfort of back and waist, the seat should have good back support. Whereas for the hip, the craftsman suggested to use the seat with thick and wider sleeper, so they can sit comfortably. For foot problems, to relieve the pain for their free feet, it is suggested to use a bench that functions as foot rest; and for the sewing feet, it is suggested to give heels support so the sewers' heels can be free from strain while sewing.
\end{abstract}

Keywords: pain and discomfort, musculoskeletal disorders, nordic musculoskeletal questionnaire (NMQ), rapid upper limb assessment (RULA), sewing operator

\begin{abstract}
ABSTRAK
Rasa nyeri dan ketidaknyamanan dalam bekerja kerap dialami pada pengrajin keset kain limbah di Pringapus, Semarang. Maka dari itu, pada penelitian ini dilakukan identifikasi kondisi kerja serta postur tubuh para pengrajin melalui pengamatan kondisi kerja termasuk fasilitas kerja yang digunakan, serta wawancara untuk menemukan keluhan dengan Nordic Musculoskeletal Questionnaire (NMQ) sebagai acuan. Hasil identifikasi menjadi input bagi rapid upper limb assessment (RULA) worksheet untuk menentukan tingkat resiko yang dialami oleh pengrajin. Hasil RULA menunjukkan keempat kondisi kerja berada pada level 2 yang mengindikasikan bahwa pekerja berada dalam postur kerja yang beresiko menyebabkan cedera akibat salah satu postur tubuh yang tidak baik. Berdasarkan analisis dari fishbone diagram, untuk mengatasi keluhan di area leher dan bahu, pengrajin disarankan melakukan penyesuaian tinggi meja dan kursi yang berdasarkan hasil pengamatan tidak sesuai postur tubuh pengrajin. Untuk keluhan di area punggung, dan pinggang, disarankan agar kursi memiliki bantalan punggung untuk menyangga punggung pengrajin. Sedangkan untuk pinggul disarankan kursi diberi bantalan yang cukup tebal dan lebih lebar agar pengrajin berada dalam posisi duduk yang nyaman. Sedangkan untuk keluhan di area kaki, untuk disarankan kaki yang bebas diberi penyangga sehingga tidak menggantung, sedangkan kaki yang menginjak pedal diberi penyangga di area tumit agar tumit tidak menahan beban akibat posisi menekan pedal yang lama.
\end{abstract}

Kata kunci: nyeri dan ketidaknyamanan otot, nordic musculoskeletal questionnaire (NMQ), rapid upper limb assessment (RULA), penjahit keset. 


\section{PENDAHULUAN}

Pengrajin kain limbah di Pringapus, Semarang, adalah salah satu cluster Usaha Kecil dan Menengah (UKM) dengan jumlah pengrajin sebanyak kurang lebih 600 UKM, yang semuanya merupakan industri skala rumah tangga. Keberadaan sentra ini didukung oleh keberadaan beberapa pabrik tekstil besar di sekitar kecamatan Pringapus maupun di Kabupaten Semarang. Sentra pengrajin kain limbah pabrik kecamatan Pringapus ini telah beroperasi selama 12 (dua belas) tahun, dimana saat ini sebagian besar pengrajin memproduksi keset (baik keset motif maupun keset biasa), dan sebagian kecil yang lain memproduksi produk lain seperti celana hawai, selimut, boneka, tatakan piring, dan lain sebagainya.

Hasil observasi awal yang dilakukan pada para pengrajin, ditemukan bahwa para pengrajin merasakan rasa nyeri dan ketidaknyamanan sebagai dampak dari pekerjaan menjahit yang dilakukan. Berdasarkan berbagai hasil penelitian mengenai nyeri dan ketidaknyamanan, para pekerja secara umum memiliki keluhan tidak nyaman atau rasa nyeri akibat pekerjaan yang dilakukannya, dan hal dapat menjadi pemicu masalah kesehatan lebih lanjut (Denis, St-Vincent, Imbeau, Jetté, \& Nastasia, 2008 ). Keluhan ini dikenal dengan istilah Cummulative Trauma Disoders (CTDs) yaitu gangguan kondisi fisik yang dirasakan oleh tulang, otot, tendon, syarat ataupun bagian tubuh lainnya sebagai akibat dari penggunaan bagian tubuh yang tidak tepat secara berulang (Adam, 2012). Cummulative Trauma Disoders (CTDs) ini bukanlah gejala klinis, istilah ini dikenal juga dengan istilah overuse syndrome, Musculo Skeletal Disorders (MSDs) atau Repetitive Strain Injuries (RSIs), Work-related Upper Extremity Disorders (UEDs). CTDs merupakan rasa nyeri karena kumpulan cedera pada sistem muskuloskeletal extremitas akibat gerakan kerja biomekanika berulang-ulang melampaui kapasitas (Adam, 2012) (Wichaksana \& Darmadi, 2002). Cedera ini dapat mengenai otot, tendon, ligamen, saraf, pembuluh darah di leher, bahu, lengan, siku, pergelangan dan jari tangan. Cedera berupa radang dan rasa nyeri yang dialami oleh pekerja dapat mengurangi kemampuan gerak pekerja dan pada akhirnya menurunkan produktivitas.

Pekerjaan menjahit, yang sampai saat ini masih memerlukan operator untuk pengerjaannya, seringkali menyebabkan operator merasakan rasa nyeri di daerah leher, bahu, pinggang dan beberapa bagian tubuh lainnya (Li, Haslegrave, \& Corlett, 1995) (Öztürk \& Esin, 2011). Rasa nyeri dan ketidaknyamanan yang sama dialami juga oleh para pengrajin kain limbah di Pringapus, Semarang. Akan tetapi, dari hasil wawancara, rasa sakit dan ketidaknyamanan tidak sama antara satu pengrajin dengan pengrajin lainnya.

Oleh karena itu, dirasa perlu dilakukan pengamatan lebih lanjut untuk mengidentifikasi penyebabnya serta melakukan analisis mengenai hasil identifikasi. Selanjutnya diharapkan dapat diusulkan perbaikan untuk mengurangi rasa nyeri dan tidak nyaman yang dialami.

\section{METODE}

Penelitian mengenai ketidaknyamanan, rasa nyeri serta cedera yang dialami oleh pekerja, telah banyak dilakukan. Metoda untuk melakukan penilaian mengenai hal ini juga telah dikembangkan seperti Rapid Upper Limb Assessment (RULA), Nordic Musculoskeletal questionnaire, Ergonomic Assessment Survey (Essay), Job strain index (JSI), Rapid Entire Body Assessment (REBA). Setiap metoda memiliki kesesuaian penggunaan untuk kondisi tertentu dan memberikan hasil untuk analisis lanjutan bagi perbaikan sistem kerja yang lebih ergonomis. 
Pada awal penelitian, dilakukan studi literatur mengenai rasa nyeri dan ketidaknyamanan. Bersamaan dengan itu dilakukan pengamatan awal mengenai: (1) kondisi kerja pengrajin keset kain limbah; (2) posisi tubuh pengrajin saat menjahit. Selain pengamatan, dilakukan juga wawancara mengenai: (1) rasa nyeri dan ketidaknyamanan yang dialami pengrajin; (2) urutan kerja yang dilakukan untuk pembuatan produk; (3) persepsi terhadap kondisi kerja seperti cahaya, kecukupan ruangan, kemudahan pergerakan saat bekerja.

Pengamatan ini bertujuan untuk: (1) mengidentifikasi apakah faktor kondisi kerja merupakan hal yang mempengaruhi perbedaan keluhan yang dialami oleh satu pengrajin dengan pengrajin lainnya; (2) untuk mengidentifikasi apakah posisi tubuh setiap penjahit sama atau berbeda, dan apakah hal ini berpengaruh terhadap keluhan yang dialami.

Wawancara yang dilakukan untuk mengumpulkan data mengenai: (1) rasa nyeri dan ketidaknyamanan untuk setiap pengrajin yang dijadikan sampel; (2) urutan kerja pembuatan produk; (3) cara kerja yang dipengaruhi oleh kondisi kerja.

Untuk wawancara mengenai rasa nyeri dan ketidaknyamanan, daftar pertanyaan wawancara diadaptasikan dari pertanyaan yang terdapat pada metoda Nordic Musculoskeletal questionnaire dan pengamatan didasarkan pada Rapid Upper Limb Assessmen atau RULA.

The Nordic Musculoskeletal Questionnaire (MSQ) digunakan secara luas untuk mengukur keluhan yang dialami otot. Kuesioner ini berisi pertanyaan mengenai permasalahan atau keluhan yang dialami otot di sembilan area tubuh termasuk leher, bahu, siku, pergelangan tangan, punggung bagian atas dan bawah, pinggul, lutut, kaki atau pergelangan kaki di minggu terakhir dan selama satu tahun terakhir. Alat ini bukan digunakan sebagai alat diagonosa klinis (Crawford, 2007), hanya untuk mengetahui keluhan permasalahan otot yang dialami seseorang.

Pada penelitian ini, pertanyaan selama wawancara untuk mengidentifikasi rasa nyeri mengacu pada MSQ, dengan daftar pertanyaan terdiri dari: (1) apakah anda memiliki keluhan nyeri dalam 12 bulan terakhir untuk: (a) leher, (b) bahu, (c) siku, (d) tangan atau pergelangan tangan, (e) punggung bagian atas, (f) punggung bagian bawah, (g) pinggul dan/atau pinggang, (h) salah satu kaki atau keduanya, (i) pergelangan kaki; (2) apakah anda memiliki keluhan nyeri dalam seminggu terakhir untuk: (a) leher, (b) bahu, (c) siku, (d) tangan atau pergelangan tangan, (e) punggung bagian atas, (f) punggung bagian bawah, (g) pinggul dan/atau pinggang, (h) salah satu kaki atau keduanya, (i) pergelangan kaki; (3) apakah anda tidak dapat melakukan kegiatan sehari-hari dalam 12 bulan terakhir akibat dari keluhan: (a) leher, (b) bahu, (c) siku, (d) tangan atau pergelangan tangan, (e) punggung bagian atas, (f) punggung bagian bawah, (g) pinggul dan/atau pinggang, (h) salah satu kaki atau keduanya, (i) pergelangan kaki.

RULA (rapid upper limb assessment) merupakan sebuah metoda survey yang dikembangkan untuk investigasi ergonomi di tempat kerja berkaitan dengan ketidaknyamanan pekerja yang dapat menyebabkan resiko CTDs (McAtamney \& Corlett, 1993). Metoda ini tidak memerlukan alat khusus untuk melakukan penilaian. Alat ini menguji kecenderungan pekerja terhadap resiko cedera pada postur, gaya, penggunaan otot, dan pergerakan pekerja pada saat melakukan pekerjaannya. Hasil analisis akan mengindikasikan derajat kencenderungan pekerja mengalami resiko tersebut, hasilnya dapat digunakan untuk mengurangi resiko cedera fisik yang dapat dialami oleh pekerja.

Pertanyaan yang diajukan pada metoda RULA terdiri dari pertanyaan untuk mengetahui beban serta kekuatan yang harus dikeluarkan oleh Upper arm right and left, lower arm right and left, wrist right and left, muscle use and force for arm right and left, neck, neck twist, neck side bend. Pada penelitian ini, digunakan RULA worksheet sebagai alat pengamatan. 
Tindakan level 1 - dengan skor RULA 1-2 mengindikasikan pekerja memiliki postur kerja yang baik dan tidak memiliki resiko dari sikap kerjanya.

Tindakan level 2 - dengan skor RULA 3-4 mengindikasikan bahwa pekerja berada dalam postur kerja yang beresiko menyebabkan cedera akibat salah satu postur tubuh yang tidak baik. Memerlukan investigasi lebih lanjut untuk perbaikannya.

Tindakan level 3 - dengan skor RULA 5-6 mengindikasikan bahwa pekerja berada dalam postur kerja yang buruk yang dapat menyebabkan cedera, untuk itu perlu dilakukan investigasi dan perubahan segera untuk menghindarkan pekerja dari cedera.

Tindakan level 4 - dengan skor RULA 7-8 mengindikasikan pekerja berada dalam postur kerja yang terburuk dan akan segera menyebabkan cedera karenanya. Untuk itu perlu dilakukan investigasi dan perubahan segera untuk menghindarkan pekerja dari cedera.

Selanjutnya hasil wawancara dan pengamatan akan dirangkum dalam sebuah tabel untuk mempermudah analisis yang kemudian menjadi input untuk pengolahan menggunakan metoda RULA. Hasilnya akan dipetakan pada fishbone diagram. Analisis lanjutan dilakukan untuk merumuskan penyebab ketidaknyamanan dan usulan perbaikan kondisi untuk mengurangi ketidaknyamanan dan rasa nyeri.

\section{HASIL DAN PEMBAHASAN}

\section{Hasil Pengamatan dan Wawancara}

Populasi pengrajin yang menjadi objek penelitian adalah pengrajin keset di Pringapus, Semarang yang menjadi binaan dari PT. Permodalan Madani Nasional dengan jumlah kurang lebih 40 orang terdiri dari 38 wanita dan 2 orang pria. Teknik sampling yang digunakan adalah purposive sampling atau pengambilan sampel secara sengaja sesuai dengan persyaratan sampel yang diperlukan. Adapun persyaratan yang diperlukan adalah kemudahan dalam pengumpulan data. Artinya pada saat pengamatan dan wawancara dilakukan, pengrajin berada di tempat dan sedang melakukan pekerjaan menjahit dan lokasi mudah dijangkau antara satu pengrajin dengan pengrajin lainnya.

Pengrajin rata-rata bekerja selama 8-10.5 jam sehari, dengan hari kerja 5-6 hari seminggu yaitu dari Senin sampai Sabtu. Berikut adalah rata-rata jam pengerjaan keset oleh pengrajin berdasarkan hasil wawancara (Tabel 1):

Tabel 1

Waktu Pengerjaan Keset oleh Pengrajin

\begin{tabular}{lll}
\hline Waktu pembuatan & Jam pengerjaan & Lama waktu \\
\hline Pagi & $08.00-12.00$ & $3-4$ jam \\
Siang & $13.30-17.00$ & $2-3,5 \mathrm{jam}$ \\
Sore & $18.30-21.00$ & $2-3 \mathrm{jam}$ \\
Waktu rata-rata yang digunakan untuk pembuatan keset/hari & $8-10.5 \mathrm{jam}$ \\
\hline
\end{tabular}

Berdasarkan hasil wawancara dengan pengrajin dan petugas Koperasi dalam sehari pengrajin bisa menghasilkan 8 buah, 10 buah, dan ada juga yang bisa menghasilkan 15 buah. Perbedaan jumlah ini dipengaruhi oleh ukuran keset yang dibuat yaitu kecil (berat hasil akhir 2-3 ons), sedang (berat hasil akhir 3-5 ons), besar (berat hasil akhir 5.5-6 ons), dan lebar (berat hasil akhir > 6 ons). 
Sedangkan untuk keset motif, dalam sehari paling banyak 3 buah keset motif dihasilkan, sedangkan rata-rata jumlah produksi adalah 2 keset per hari dan rata-rata berat produk jadi $=5-7$ ons.

Lamanya waktu yang dialokasikan untuk menghasilkan keset, mendorong pengrajin dalam posisi statis yang lama pada saat menjahit. Hal ini diperkirakan sebagai pendorong dari keluhan nyeri dan ketidaknyamanan yang dialami oleh pengrajin. Selanjutnya dilakukan pengamatan berdasarkan RULA worksheet, dan wawancara yang menggunakan NMQ sebagai referensi. Tabel 2 menunjukkan rangkuman kondisi postur pengrajin dibandingkan dengan posisi leher, kondisi statis yang dialami, serta keluhan pada kondisi tersebut.

Tabel 2

Hasil Pengamatan untuk Postur, Posisi Leher, Kondisi Statis serta Keluhan yang Dialami

\begin{tabular}{lllll} 
Hasil Pengamatan & $\begin{array}{c}\text { Sikap Duduk } \\
\text { (Postur) }\end{array}$ & \multicolumn{1}{c}{ Posisi Leher } & Kondisi Statis & \multicolumn{1}{c}{ Keluhan } \\
\hline Kondisi 1 & Bungkuk & $\begin{array}{l}\text { Tunduk lebih dari 20 } \\
\text { derajat }\end{array}$ & Lebih dari 10 menit & $\begin{array}{l}\text { Leher dan bahu } \\
\text { sakit, pusing }\end{array}$ \\
\hline Kondisi 2 & Bungkuk & $\begin{array}{l}\text { Tunduk sampai 20 } \\
\text { derajat }\end{array}$ & Lebih dari 10 menit & $\begin{array}{l}\text { Leher dan bahu } \\
\text { sakit, pusing }\end{array}$ \\
\hline Kondisi 3 & Tegak & $\begin{array}{l}\text { Tunduk kurang dari } \\
\text { 20 derajat }\end{array}$ & Lebih dari 10 menit & bahu sakit \\
\hline & & Tunduk kurang dari & Lebih dari 10 menit & bahu sakit \\
\hline Kondisi 4 & Tegak & 20 derajat & & \\
\hline
\end{tabular}

Pada tabel berikutnya (Tabel 3), dirangkum keluhan yang dialami oleh pengrajin pada beberapa kondisi kerja dikaitkan dengan kondisi kaki yang bebas (tidak menginjak pedal jahit) dan kaki yang menginjak pedal. Secara umum, kursi tidak memiliki foot rest, kaki yang bebas seringkali menggantung atau sedikit jinjit sehingga mengalami kebas, pegal serta bengkak. Sedangkan untuk kaki yang digunakan menginjak pedal, mengalami ketegangan di area betis dan paha karena bagian jari kaki harus berada pada posisi mengangkat, dan tumit menahan posisi tersebut, dimana tumit lebih rendah dibandingkan jari kaki dalam waktu yang cukup lama.

Tabel 3

Hasil Pengamatan dan Keluhan Berdasarkan Sikap Kerja dan Kondisi Kaki

\begin{tabular}{lllll}
\hline Hasil Pengamatan & $\begin{array}{l}\text { Sikap Duduk } \\
\text { (Postur) }\end{array}$ & $\begin{array}{l}\text { Kaki yang } \\
\text { bebas }\end{array}$ & Kaki untuk Pedal & Keluhan \\
\hline Kondisi 1 & Bungkuk & di lantai & $\begin{array}{l}\text { tumit lebih rendah dari } \\
\text { jari, otot betis tegang }\end{array}$ & $\begin{array}{l}\text { Betis dan paha } \\
\text { sebelah kanan } \\
\text { sakit }\end{array}$ \\
\hline Kondisi 2 & Bungkuk & di lantai & $\begin{array}{l}\text { tumit lebih rendah dari } \\
\text { jari, otot betis tegang }\end{array}$ & $\begin{array}{l}\text { Betis dan paha } \\
\text { sebelah kanan } \\
\text { sakit, kaki kiri } \\
\text { pegal atau } \\
\text { bengkak }\end{array}$ \\
\hline Kondisi 3 & & & $\begin{array}{l}\text { Betis dan paha } \\
\text { sebelah kanan } \\
\end{array}$ \\
& Tegak & di lantai & tumit lebih rendah dari \\
& & jari, otot betis tegang & bengkak \\
\hline
\end{tabular}




\begin{tabular}{|c|c|c|c|c|}
\hline Kondisi 4 & Tegak & $\begin{array}{l}\text { diberi } \\
\text { penyangga } \\
\text { dengan tinggi } \\
\text { kurang lebih } \\
10 \mathrm{~cm}\end{array}$ & $\begin{array}{l}\text { pedal diberi alat } \\
\text { penyimpan, dan tumit } \\
\text { diberi penyangga } \\
\text { sehingga sejajar dengan } \\
\text { dengan jari kaki. }\end{array}$ & $\begin{array}{l}\text { punggung bagian } \\
\text { tengah pegal }\end{array}$ \\
\hline
\end{tabular}

Tabel 4 berisi rangkuman hasil pengamatan dan wawancara berdasarkan postur tubuh, kondisi meja tempat penjahit menyimpan mesin jahit dilihat dari tingginya dibandingkan dengan tinggi tubuh penggunanya (pengrajin). Selain itu, dibandingkan dengan kondisi kursi yang digunakan oleh pengrajin berdasarkan tinggi tempat duduknya, tersedianya foot rest atau tidak untuk kaki yang bebas, kondisi tempat duduk apakah tersedia bantalan atau tidak, lebarnya cukup tidak untuk pengguna, serta tersedianya backrest atau tidak. Berikut hasil rangkumannya:

Tabel 4

Hasil Pengamatan Berdasarkan Kondisi Meja dan Kursi Serta Keluhan yang Dialami

\begin{tabular}{|c|c|c|c|c|}
\hline $\begin{array}{c}\text { Hasil } \\
\text { Pengamatan }\end{array}$ & $\begin{array}{l}\text { Sikap } \\
\text { Duduk } \\
\text { (Postur) }\end{array}$ & $\begin{array}{l}\text { Meja yang } \\
\text { digunakan }\end{array}$ & $\begin{array}{l}\text { Kursi yang } \\
\text { digunakan }\end{array}$ & Keluhan \\
\hline Kondisi 1 & Bungkuk & $\begin{array}{l}\text { rendah } \\
\text { dibandingkan } \\
\text { ukuran tinggi } \\
\text { badan }\end{array}$ & $\begin{array}{l}\text { Rendah, sesuai dengan } \\
\text { tinggi meja, memiliki } \\
\text { bantalan duduk yang } \\
\text { baik, ada backrest }\end{array}$ & $\begin{array}{l}\text { punggung bagian } \\
\text { tengah pegal/sakit }\end{array}$ \\
\hline Kondisi 2 & Bungkuk & $\begin{array}{l}\text { Tinggi meja } \\
\text { cukup }\end{array}$ & $\begin{array}{l}\text { tinggi kursi cukup, } \\
\text { tidak ada foot rest, } \\
\text { tidak ada bantalan yang } \\
\text { cukup, lebar kurang }\end{array}$ & $\begin{array}{l}\text { pinggul dan } \\
\text { pinggang sakit }\end{array}$ \\
\hline Kondisi 3 & Tegak & $\begin{array}{l}\text { Tinggi meja } \\
\text { cukup }\end{array}$ & $\begin{array}{l}\text { tinggi kursi cukup, } \\
\text { tidak ada foot rest, } \\
\text { tidak ada bantalan yang } \\
\text { cukup, lebar kurang, } \\
\text { tidak ada back rest }\end{array}$ & $\begin{array}{l}\text { pinggul dan } \\
\text { pinggang sakit }\end{array}$ \\
\hline Kondisi 4 & Tegak & $\begin{array}{l}\text { Tinggi meja } \\
\text { cukup }\end{array}$ & $\begin{array}{l}\text { tinggi kursi cukup, } \\
\text { bantalan cukup, tidak } \\
\text { ada back rest }\end{array}$ & $\begin{array}{l}\text { punggung bagian } \\
\text { tengah pegal/sakit }\end{array}$ \\
\hline
\end{tabular}

Hasil pengamatan dan wawancara juga mencakup lingkungan yang dianggap mendukung proses pembuatan keset oleh pengrajin. Yang dimaksud lingkungan pada artikel ini adalah pencahayaan yang digunakan di siang hari dan di malam hari, pergerakan pengrajin selama melakukan aktivitas menjahit, serta keluhan yang dialami terkait dengan kondisi lingkungan tersebut (Tabel 5).

Tabel 5

Kondisi Lingkungan dan Keluhan yang Dialami

\begin{tabular}{llllll}
\hline $\begin{array}{c}\text { Hasil } \\
\text { Pengamatan }\end{array}$ & $\begin{array}{c}\text { Pencahayaan } \\
\text { Siang hari }\end{array}$ & $\begin{array}{c}\text { Pencahayaan } \\
\text { Malam Hari }\end{array}$ & Area kerja & Keluhan & $\begin{array}{c}\text { Pergerakan } \\
\text { Pengrajin }\end{array}$ \\
\hline Kondisi 1 & $\begin{array}{l}\text { Cukup (jika } \\
\text { cuaca cerah) }\end{array}$ & $\begin{array}{l}\text { Jarak sumber } \\
\text { cahaya terlalu } \\
\text { jauh }\end{array}$ & $\begin{array}{l}\text { Dinding gelap, } \\
\text { menyerap } \\
\text { cahaya }\end{array}$ & $\begin{array}{l}\text { tidak merasa } \\
\text { ada keluhan }\end{array}$ & $\begin{array}{l}\text { Luas, penempatan } \\
\text { alat kerja terlau jauh } \\
\text { satu sama lain }\end{array}$ \\
\hline
\end{tabular}




\begin{tabular}{llllll}
\hline Kondisi 2 & $\begin{array}{l}\text { Relatif silau di } \\
\text { siang hari }\end{array}$ & $\begin{array}{l}\text { Sumber cahaya } \\
\text { terlalu dekat } \\
\text { dengan mata }\end{array}$ & $\begin{array}{l}\text { Dinding terang, } \\
\text { cahaya bisa } \\
\text { memantul } \\
\text { dengan baik }\end{array}$ & $\begin{array}{l}\text { pusing, mata } \\
\text { cepat lelah }\end{array}$ & $\begin{array}{l}\text { Cukup, penempatan } \\
\text { alat kerja baik }\end{array}$ \\
\hline Kondisi 3 & $\begin{array}{l}\text { Cukup (jika } \\
\text { cuaca cerah) }\end{array}$ & $\begin{array}{l}\text { sumber cahaya } \\
\text { cukup }\end{array}$ & $\begin{array}{l}\text { Dinding gelap, } \\
\text { menyerap } \\
\text { cahaya }\end{array}$ & $\begin{array}{l}\text { mata cepat } \\
\text { lelah (sepet) } \\
\text { dan } \\
\text { mengantuk }\end{array}$ & $\begin{array}{l}\text { Cukup, penempatan } \\
\text { alat kerja baik }\end{array}$ \\
\hline Kondisi 4 & Cukup (jika & $\begin{array}{l}\text { sumber cahaya } \\
\text { kurang (terlalu } \\
\text { jauh dan kurang } \\
\text { terang) }\end{array}$ & $\begin{array}{l}\text { Dinding terang, } \\
\text { cahaya bisa } \\
\text { memantul } \\
\text { dengan baik }\end{array}$ & $\begin{array}{l}\text { Mata cepat } \\
\text { lelah di } \\
\text { malam hari }\end{array}$ & $\begin{array}{l}\text { Cukup, penempatan } \\
\text { alat kerja baik }\end{array}$ \\
& & & & & \\
\hline
\end{tabular}

\section{Nilai RULA}

Hasil wawancara dan pengamatan kemudian dimasukkan ke dalam RULA Assessment Worksheet untuk menentukan nilai RULA pada setiap kondisi hasil pengamatan. Adapun hasil skor RULA untuk sebagai berikut (Tabel 6):

Tabel 6

Nilai RULA untuk Setiap Kondisi Kerja

\begin{tabular}{lcccc}
\hline \multicolumn{1}{c}{ Assesment } & Kondisi $\mathbf{1}$ & Kondisi 2 & Kondisi 3 & Kondisi 4 \\
\hline A. Arm and Wirst Analysis & 1 & & & \\
$\quad$ Upper Arm Position & 1 & 1 & 1 & 1 \\
Lower Arm Position & 1 & 1 & 1 & 1 \\
Wirst Position & 0 & 0 & 0 & 1 \\
Wrist Twist & 2 & 2 & 2 & 2 \\
Wirst \& Arm Score & & & & \\
\hline B. Neck, Trunk and Leg Analysis & 3 & 2 & 2 & 2 \\
Neck Position & 3 & 3 & 2 & 2 \\
Trunk Position & 1 & 2 & 2 & 1 \\
Legs & 4 & 5 & 3 & 2 \\
Neck, Trunk and Leg Score & & & 3 & 3 \\
\hline Final Score & $\mathbf{4}$ & $\mathbf{4}$ & 3 \\
\hline
\end{tabular}

Nilai akhir dari setiap kondisi berada di rentang 3-4; hal ini mengindikasikan bahwa pekerja berada dalam postur kerja yang beresiko menyebabkan cedera akibat salah satu postur tubuh yang tidak baik. Untuk itu diperlukan investigasi lebih lanjut untuk perbaikannya. Untuk investigasi lanjutan, hasil pengamatan dan wawancara akan dipetakan dalam fishbone diagram, yang selanjutnya akan disampaikan rekomendasi perbaikan yang mungkin dilakukan. Fishbone diagram akan membantu melihat penyebab keluhan nyeri dan ketidaknyamanan yang dialami pengrajin.

\section{Analisis dan Rekomendasi}

Hasil pengumpulan data yang dirangkum pada Tabel 1-5, dianalisis kembali dengan mempetakannya ke dalam fishbone diagram. Fishbone diagram tersebut didasarkan pada keluhan yang umum dialami oleh pengrajin yaitu: rasa nyeri pada leher, rasa nyeri/pegal pada bahu, rasa pegal 
pada punggung tengah, rasa pegal/nyeri pada betis dan paha, kaki bengkak, serta rasa nyeri pada pinggul dan pinggang. Hasil analisis digunakan untuk menyusun rekomendasi yang diusulkan bagi pengrajin sehingga dapat mengurangi bahkan menghilangkan keluhan.

Gambar 1 menjelaskan penyebab rasa nyeri di leher yang dialami beberapa pengrajin atas kondisi statis, posisi tubuh, kondisi kursi, posisi leher, dan kondisi meja. Penyebab utama dari rasa nyeri di leher (gambar 1) adalah posisi duduk yang membungkuk, dan posisi menunduk dengan sudut lebih dari 20 derajat. Dan hal ini diperparah karena pengrajin seringkali berada dalam posisi tetap atau statis lebih dari 10 menit untuk menjahit keset. Untuk itu, disarankan bahwa pengrajin yang berada dalam kondisi 1 untuk menyesuaikan tinggi meja dengan tinggi badan, begitu juga dengan tinggi kursi untuk memperbaiki postur tubuh yang membungkuk.

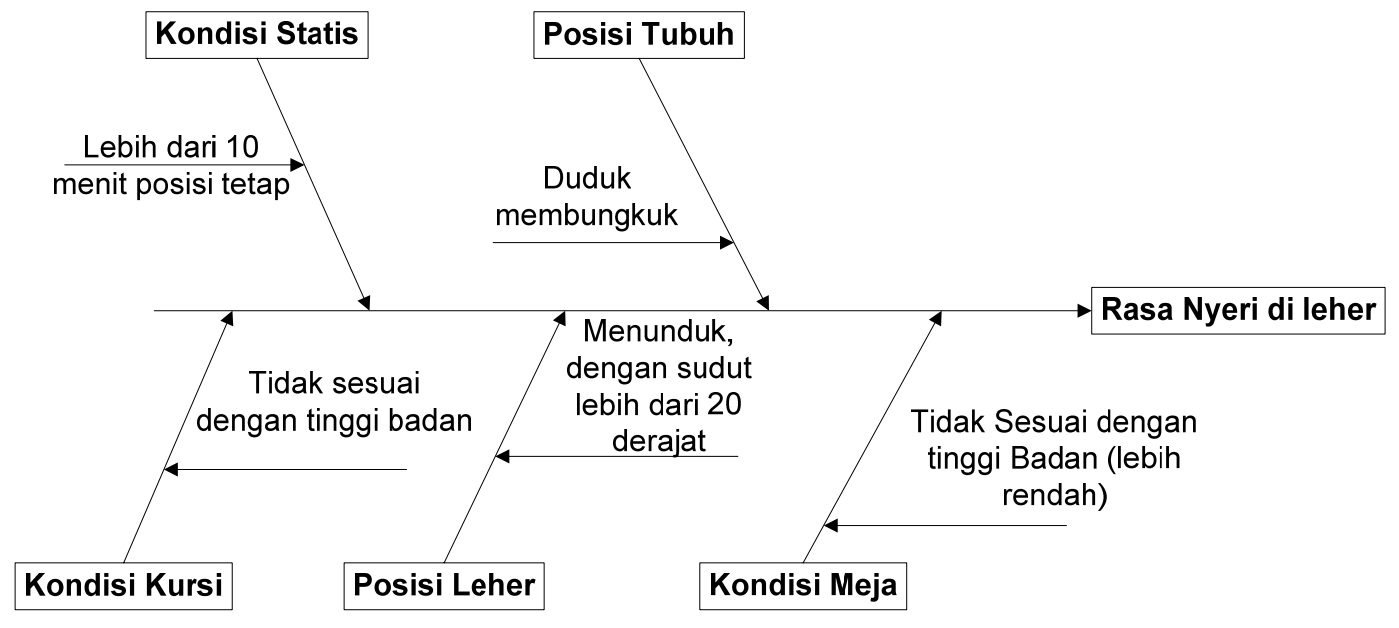

Gambar 1. Fishbone diagram untuk rasa nyeri di leher (sumber: pengolahan data).

Penyebab utama dari rasa nyeri atau pegal di bahu (Gambar 2), dikarenakan posisi statis yang dialami pengrajin saat memproduksi keset, serta kondisi kursi dan meja yang tidak sesuai dengan tinggi badan pengrajin yang mendorong sikap bungkuk pada saat menjahit. Rekomendasi yang diusulkan sama dengan kondisi 1 yaitu pengrajin diharapkan untuk menyesuaikan tinggi meja dan tinggi kursi dengan tinggi badan pengrajin.

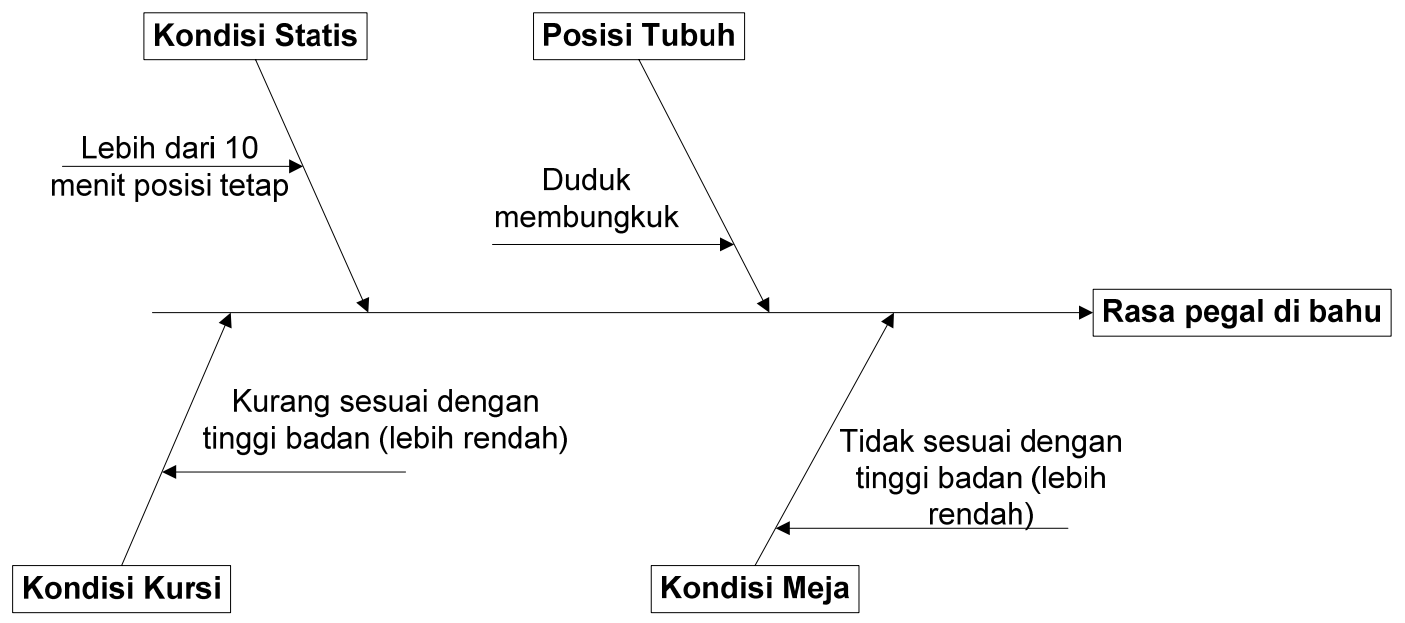

Gambar 2. Fishbone diagram untuk rasa pegal di bahu (sumber: pengolahan data). 
Rasa sakit, pegal di betis dan paha (Gambar 3) dialami oleh kaki sebelah kanan atau oleh kaki yang digunakan untuk menginjak pedal. Hal ini dikarenakan posisi kaki tidak sejajar, dimana tumit lebih rendah dari jari penginjak pedal dan tumit dalam posisi menahan kaki selama menjahit. Hal ini menyebabkan betis dalam keadaan tegang terus-menerus, begitu juga paha bagian belakang. Untuk kondisi ini, disarankan tumit diberi penyangga agar posisi kaki sejajar dan tumit tidak perlu menahan kaki. Hal ini akan mengurangi dan menghindarkan pengrajin dari rasa sakit, pegal di betis dan paha untuk kaki yang digunakan menginjak pedal.

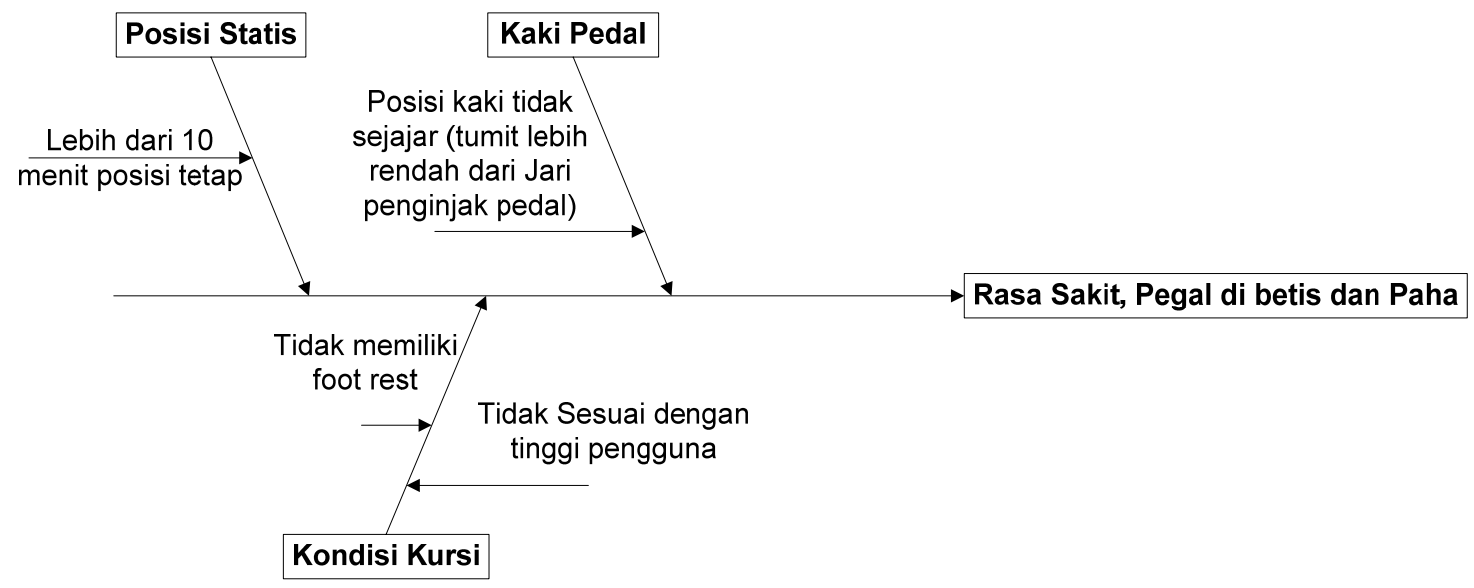

Gambar 3. Fishbone diagram untuk rasa sakit, pegal di betis dan paha

(sumber: pengolahan data).

Selanjutnya untuk kaki yang bebas (atau tidak digunakan menginjak pedal jahit) (Gambar 4), karena kursi tidak memiliki foot rest, dan tinggi kursi yang kurang sesuai dengan tinggi pengrajin (lebih tinggi dari tinggi popliteal), kaki bebas cenderung menggantung. Pada kondisi statis yang cukup lama, hal ini menyebabkan kaki pegal dan jika terus menerus dapat menyebabkan pembengkakan akibat penumpukan darah di area kaki. Hal ini dapat dikurangi dengan menambahkan foot rest atau penyangga bagi kaki yang bebas. Tinggi penyangga disesuaikan dengan kebutuhan setiap pengrajin dengan mempertimbangkan tinggi badan dan tinggi kursi yang digunakan. Perlu diperhatikan juga tinggi meja dan area kosong di bawah meja agar tidak menghalangi gerakan kaki pengrajin.

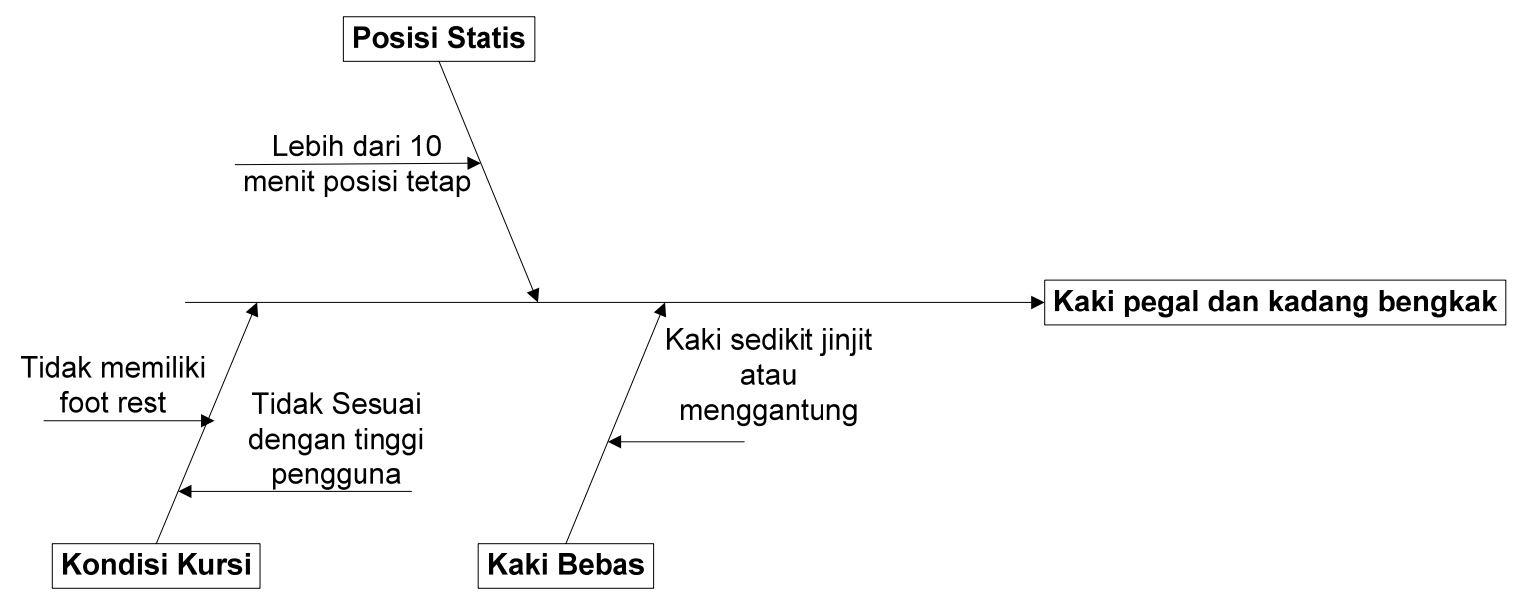

Gambar 4. Fishbone Diagram untuk kaki pegal dan bengkak (sumber: pengolahan data). 
Untuk rasa pegal di bagian bawah tubuh terutama di pinggul dan pinggang secara umum dikarenakan kursi yang digunakan tidak memiliki bantalan yang empuk dan kurang lebar sehingga tidak dapat menyangga tubuh pengrajin dalam posisi duduk dengan baik (Gambar 5). Saat ini pengrajin banyak yang menggunakan kursi plastik tanpa bantalan dan sandaran, serta lebar kursi kurang nyaman untuk duduk dalam waktu lama. Sedangkan untuk keluhan di bagian punggung disebabkan kursi tidak memiliki sandaran yang dapat membantu menyangga punggung pengrajin. Kondisi statis yang cukup lama yang dialami oleh pengrajin menyebabkan pengrajin harus menahan punggung dalam jangka waktu yang tidak sebentar, Hal ini mendorong keluhan rasa nyeri di punggung. Hal yang disarankan adalah, pengrajin dapat menggunakan kursi yang memiliki bantalan punggung dan bantalan duduk yang dapat menyangga tubuh dengan baik. Diharapkan rasa nyeri dan pegal dapat berkurang bahkan dihilangkan dengan digantinya kursi yang digunakan.

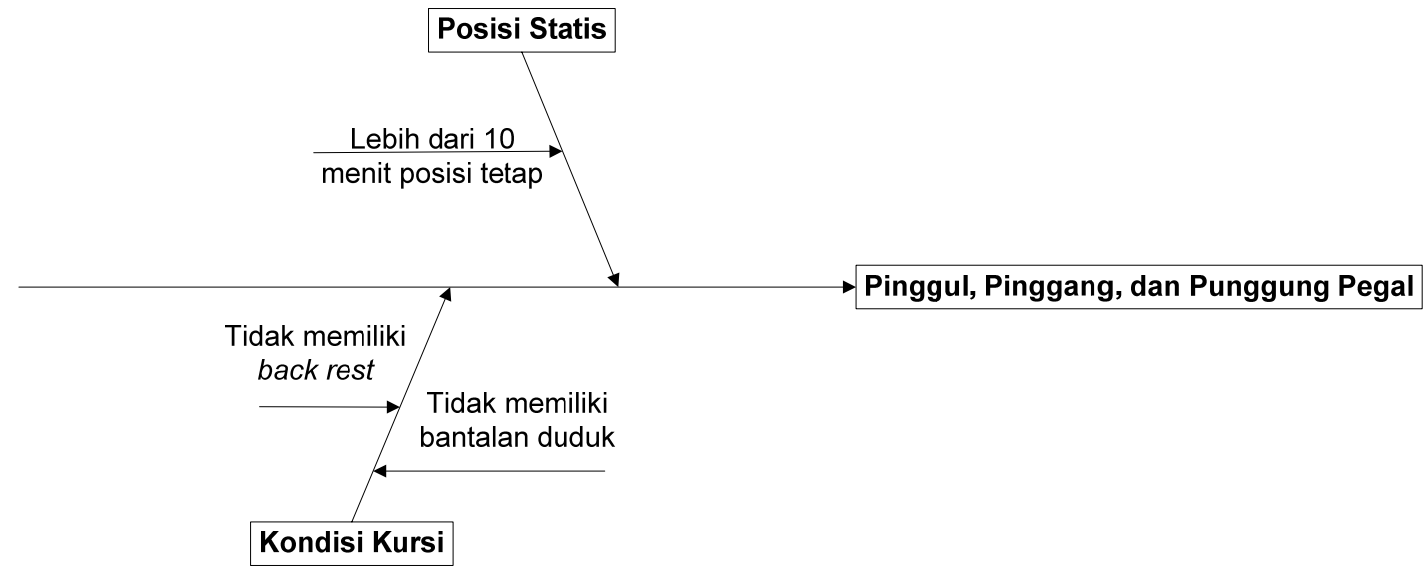

Gambar 5. Fishbone diagram untuk rasa pegal di pinggul, pinggang, dan punggung (sumber: pengolahan data).

Berdasarkan hasil pengamatan dan wawancara yang mengacu pada NMQ, penilaian kondisi menggunakan metoda RULA, serta pemetaan menggunakan fishbone diagram, disampaikan saran yang berkaitan dengan perbaikan dan penambahan fasilitas kerja. Penggantian fasilitas kerja meliputi meja dan kursi yang digunakan agar lebih ergonomis dan sesuai dengan kebutuhan pengrajin. Sedangkan penambahan fasilitas adalah penambahan penyangga kaki baik untuk kaki yang bebas maupun kaki yang digunakan untuk menginjak pedal. Pelaksanaan saran ini penting, akan tetapi untuk melihat apakah keluhan yang dialami masih terjadi atau tidak, perlu dilakukan pengamatan kembali setelah perbaikan dilakukan.

\section{PENUTUP}

Berdasarkan hasil pengamatan, wawancara, dan pengolahan data, dapat disimpulkan bahwa kondisi dan fasilitas kerja para pengrajin dapat dikelompokkan ke dalam empat kondisi. Hasilnya, tidak semua pengrajin mengalami keluhan yang sama, karena kondisi kerja termasuk kursi dan meja yang digunakan, sikap dan postur tubuh pengrajin berbeda satu sama lain. Sehingga dapat disimpulkan, keluhan berbeda yang dialami oleh satu pengrajin dengan pengrajin lainnya disebabkan oleh perbedaan kondisi kerja dan fasilitas kerja yang dimiliki serta sikap atau postur tubuh saat melakukan pekerjaan.

Untuk kondisi 1, saran perbaikan untuk fasilitas kerja adalah penyesuaian tinggi kursi dan meja dengan tinggi tubuh pengrajin. Jangan terlalu rendah karena akan mendorong sikap bungkuk 
pada saat pengrajin menjahit keset. Karena jam kerja yang lama, sikap bungkuk ini akan mendorong rasa pegal/nyeri di leher, di mana sudut bungkuk lebih dari 20 derajat.

Untuk kondisi 2, saran perbaikannya adalah penyesuaian tinggi kursi dan meja dengan tubuh pengrajin sehingga bahu tidak pegal akibat sikap bungkuk pengrajin.

Pada kondisi 3, kursi yang rendah memungkinkan kaki ditopang oleh lantai. Sedangkan kaki yang menginjak pedal, harus diberi penyangga untuk bagian tumit agar betis dan paha tidak mengalami ketegangan secara terus-menerus selama waktu menjahit. Untuk kursi yang lebih tinggi dari tinggi popliteal pengrajin, disarankan kaki yang bebas diberi penyangga (sebagai foot rest) agar tidak menggantung.

Untuk kondisi 4, diperlukan perbaikan kursi yang digunakan, yaitu yang memiliki sandaran punggung. Hal ini dapat membantu menyangga bagian punggung pengrajin sehingga mengurangi rasa pegal di bagian punggung. Kursi diberi bantalan duduk yang cukup dan lebar kursi disesuaikan dengan kebutuhan pengrajin, agar rasa pegal pada pinggul dan pinggang dapat dikurangi.

Dalam kesempatan ini, tak lupa penulis ingin mengucapkan terima kasih kepada Bapak Dani Dityawan, Bapak Octo dari PT Permodalan Madani Nasional, serta pengrajin keset di Pringapus, Semarang, atas kesempatannya melakukan penelitian ini.

\section{DAFTAR PUSTAKA}

Adam, C. (2012). Cumulative Trauma Disorder. Diakses 6 February 2012, dari http://ergonomics.about.com/: http://ergonomics.about.com/od/glossary/g/ctddef.htm

Crawford, J. O. (2007). The nordic musculoskeletal questionnaire. Occopational Medicine Oxford Journal, 300-301.

Denis, D., St-Vincent, M., Imbeau, D., Jetté, C., \& Nastasia, I. (2008 ). Intervention practices in musculoskeletal disorder prevention: A critical literature review. Applied Ergonomics, 39 (1), $1-14$.

Li, G., Haslegrave, C. M., \& Corlett, E. N. (1995). Factors affecting posture for machine sewing tasks. Applied Ergonomics, 46, 35-46.

McAtamney, L., \& Corlett, E. N. (1993). RULA: a survey method for the investigation of workrelated upper limb disorders. Applied Ergonomics, 24(2), 91-99.

Öztürk, N., \& Esin, M. N. (2011). Investigation of musculoskeletal symptoms and ergonomic risk factors among. International Journal of Industrial Ergonomics, 41, 585-591.

Saraji, J., Hassanzadeh, M. A., Pourmahabadian, M., \& Shahtaheri, S. J. (2004). Evaluation of musculoskeletal disorders risk factors among the crew of the iranian ports and shipping organization’s vessels. Acta Medica Iranica, 350-354.

Wichaksana, A., \& Darmadi, K. A. (2002). Peran Ergonomi dalam pencegahan sindrom carpal tunnel akibat kerja. Cermin Dunia Kedokteran No. 136 , 17-20. 